\title{
Correction to: Estimating Transition Probabilities from Published Evidence: A Tutorial for Decision Modelers
}

\author{
Risha Gidwani ${ }^{1,2,3}$ (1) $\cdot$ Louise B. Russell ${ }^{4,5}$ (])
}

Published online: 8 September 2020

(c) This is a U.S government work and its text is not subject to copyright protection in the United States; however, its text may be subject to foreign copyright protection 2020

\section{Correction to: PharmacoEconomics https://doi.org/10.1007/s40273-020-00937-z}

In the original version of this article a number of equations were incorrectly represented.

Equation 8 should read:

$r=\frac{-\ln (1-p)}{t}$

In Sect. 5.1 the equation describing the 12-month rate should read:

12 month rate $=\frac{-\ln (1-0.108)}{1}=0.114289$

The original article can be found online at https://doi.org/10.1007/ s40273-020-00937-z.

Risha Gidwani

rishag@rand.org

1 Department of Health Management and Policy, UCLA School of Public Health, Los Angeles, CA, USA

2 Health Economics Resource Center, VA Palo Alto Health Care System, Menlo Park, CA, USA

3 Center for Innovation To Implementation, VA Palo Alto Health Care System, Menlo Park, CA, USA

4 Department of Medical Ethics and Health Policy, Perelman School of Medicine, University of Pennsylvania, Philadelphia, USA

5 Center for Health Incentives and Behavioral Economics and Leonard Davis Institute of Health Economics, University of Pennsylvania, Philadelphia, USA
The equation directly beneath the third paragraph of the appendix should read

$r=\frac{-\ln (1-p)}{t}=\frac{-\ln (1-0.40)}{4}=0.127706$ deaths per person-year.

The original article has been corrected. 